Conclusion Treatment through 102 weeks with any of the 4 infliximab regimens plus MTX, inhibits structural joint damage. Early intervention with infliximab in pts with active disease despite MTX may protect joints during the early, rapidly-progressive, destructive phase of the disease.

\begin{tabular}{lllllll}
\multicolumn{7}{l}{ Abstract OP0087 Table 1} \\
\hline & Placebo & $\begin{array}{l}3 \text { q8 } \\
\text { wks }\end{array}$ & $\begin{array}{l}3 \text { q4 } \\
\text { wks }\end{array}$ & $\begin{array}{l}10 \text { q8 } \\
\text { wks }\end{array}$ & $\begin{array}{l}10 \text { q4 } \\
\text { wks }\end{array}$ & $\begin{array}{l}\text { All } \\
\text { Infliximab }\end{array}$ \\
\hline Total pts & 88 & 86 & 86 & 87 & 81 & 340 \\
Early RA pts & 17 & 19 & 19 & 20 & 7 & 65 \\
Pts evaluated & 12 & 10 & 16 & 17 & 6 & 49 \\
Change in TSS & 25.0 & -0.6 & -2.5 & 1.7 & -1.4 & -0.5 \\
Mean & & & & & & \\
SD & 26.8 & 8.3 & 9.8 & 5.0 & 3.5 & 7.5 \\
Median & 14.5 & -1.4 & 0.4 & 0.5 & -0.8 & 0.5 \\
p-value & & $<0.001$ & $<0.001$ & 0.004 & 0.001 & $<0.001$ \\
\hline
\end{tabular}

\section{OP0117 THE EFFECT OF ANAKINRA IN SLOWING RADIOLOGIC PROGRESSION IN RHEUMATOID ARTHRITIS PATIENTS ? EVIDENCE FROM A BOOTSTRAP ANALYSIS}

MW Cravets, E Ng, MB Bear. Department of Biostatistics, Amgen Inc., Thousand Oaks, USA

\subsection{6/annrheumdis-2001.1218}

Background Anakinra was studied in a randomised placebo-controlled study of 473 patients with rheumatoid arthritis (RA). Patients were randomised to one of 4 treatment groups (placebo, $30 \mathrm{mg}, 75 \mathrm{mg}$ or $150 \mathrm{mg}$ anakinra) and treated for 24 weeks. Radiographic assessments of the hands and wrists based on Larsen score (Larsen 1977) were collected at baseline and 24 weeks. At the end of the study, about $27 \%$ of the patients withdrew. To assess the anakinra effect on reducing joint damage, the potential influence of dropouts on the study conclusions must be taken into account.

Objectives To demonstrate that the effect of anakinra in reducing the rate of radiologic disease progression is robust and insensitive to potential biases due to losses of followup.

Methods The 3 anakinra dose groups were combined into a single treatment group which was then compared to placebo. For each treatment group, $\mathrm{x} \%$ of the missing Larsen score changes from baseline to week 24 were imputed by randomly selecting the observed change scores from the same treatment group, and the rest of the missing data were imputed similarly from the opposite treatment group. The resampled (bootstrapped) data were then analysed by an ANOVA model. This resampling procedure was repeated 1000 times, resulting in the estimation of $1000 \mathrm{p}$-values for testing the treatment effect. These $1000 \mathrm{p}$-values were then summarised to give an estimated picture of the IL-1ra treatment effect. By changing the proportion of sampling (x) systematically, the effect of anakinra on radiologic progression can be studied under different scenarios of missing data.

Results The results from all the analyses indicated that there was improvement in radiologic progression with anakinra treatment for 24 weeks. Statistical significance was maintained when up to $40 \%$ of the missing data were sampled from the opposite treatment group (mean and median p-values range from 0.021 to 0.078 , and 0.011 to 0.05 respectively).

Conclusion Anakinra has a statistically significant effect on slowing the progression of disease for 24 weeks of treatment as measured by the Larsen Score, even when as much as $40 \%$ of the missing anakinra scores are imputed with placebo values.

\section{OP0118 TREATMENT PREFERENCES FOR EARLY RHEUMATOID ARTHRITIS PATIENTS: HOW AGGRESSIVE ARE RHEUMATOLOGISTS?}

D Erkan, Y Yazici, MJ Harrison, SA Paget. Division of Rheumatology, Hospital for Special Surgery - Weill Medical College of Cornell University, New York, USA

\subsection{6/annrheumdis-2001.1219}

Background Epidemiologic and clinical data point to the need for early and aggressive DMARD treatment of rheumatoid arthritis (RA) in order to improve functional outcome and prevent joint damage.

Objectives To identify the pharmacoeconomic, physician, and geographic variables that might modify physician choice (s) of first-line therapy for early RA.

Methods A questionnaire describing 3 RA cases with differing levels of disease severity/activity was developed. Each scenario portrayed a patient of the same age/gender, but presenting with a 6-month?s history of the signs/symptoms of mild, moderate, and severe disease activity/severity. The questionnaire was mailed to rheumatologists (adult practice) ( $\mathrm{n}=995)$ within four geographical regions of the United States (Northeast-NY; South-TX; Midwest-MO/NE/KS; West-CA) who were identified through the membership directory of the American College of Rheumatology. Rheumatologists were asked to identify their choice (s) of first-line therapy for each of the case profiles, first incorporating and second not incorporating cost as a factor in their treatment decision (s).

Results 375 (37.7\%) questionnaires were returned between March 12 and April 25, 2000. Response rates were similar among the different geographical regions. The Table 1 demonstrates the use of NSAID/COX2 inhibitors and/or corticosteroids (CS) alone as well as the use of DMARD therapy (including anti-TNF medications) with or without NSAID/COX-2, and/or CS. Various combinations of only NSAID/COX2/CS/Hydroxychloroquine/Sulfasalazine as the initial treatment were cited by $53-56 \%$ for mild, 3-5\% for moderate, and 1-2\% for severe disease activity/severity. DMARD monotherapy was chosen by nearly $3 / 4$ of all rheumatologists for the treatment of mild RA, and by $40-60 \%$ for the treatment of moderate-severe RA regardless of cost issues. For severe disease activity/severity, when cost was a consideration the use of triple DMARD therapy significantly increased. Neither geographic location nor age (as a proxy for years of training) of the rheumatologist appeared to play a role in the treatment choices.

Conclusion For the first-line therapy of early RA, medication cost played no role in the choice of mono, double, or triple

\begin{tabular}{llll} 
Abstract OP0118 Table 1 & & \\
\hline & $\begin{array}{l}\text { MILD RA } \\
\text { \$not vs \$ }\end{array}$ & $\begin{array}{l}\text { MODERATE RA } \\
\text { \$not vs \$ }\end{array}$ & $\begin{array}{l}\text { SEVERE RA } \\
\text { \$not vs \$ }\end{array}$ \\
\hline NSAID/COX2/CS & $9 \%$ vs $10 \%$ (NS) & $2 \%$ vs $3 \%$ (NS) & $1 \%$ vs $1 \%$ (NS) \\
1 DMARD & $73 \%$ vs $75 \%$ (NS) & $55 \%$ vs $60 \%$ (NS) & $41 \%$ vs $47 \%$ (NS) \\
2 DMARDs & $14 \%$ vs $12 \%$ (NS) & $35 \%$ vs $26 \%$ (NS) & $45 \%$ vs $29 \%(p=0.00001)$ \\
3 DMARDs & $4 \%$ vs $3 \%$ (NS) & $8 \%$ vs $11 \%$ (NS) & $12 \%$ vs $23 \%(p=0.00002)$ \\
\hline
\end{tabular}

\$not: Cost is not a consideration, \$: Cost is a consideration, NS: Not significant. 